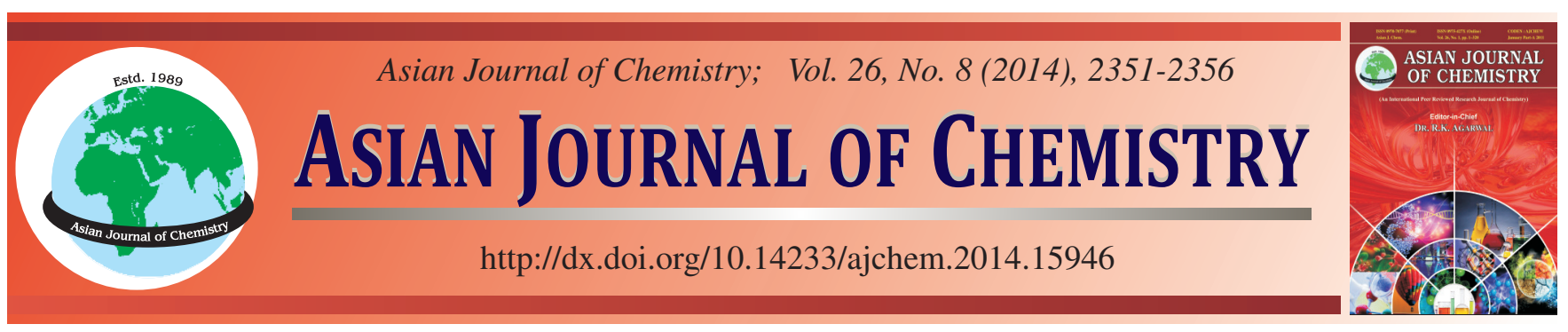

\title{
Improved Synthesis and Chromophoric Properties of Tetra- $\beta$-(2-octanyloxy)substituted Nickel Phthalocyanine
}

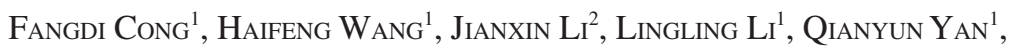
XinXin $\mathrm{ChU}^{2}$, Yanyan Meng ${ }^{2}$, Kezhi XING ${ }^{1, *}$ and Xiguang Du ${ }^{2, *}$

${ }^{1}$ Tianjin Key Laboratory of Aqua-ecology and Aquaculture, Department of Basic Science, Tianjin Agricultural University, Tianjin 300384, P.R. China

${ }^{2}$ Faculty of Chemistry, Northeast Normal University, Changchun 130024, P.R. China

*Corresponding authors: E-mail: tn_aqua_lab@aliyun.com; xgdum@aliyun.com

Received: 21 June 2013;

Accepted: 14 October 2013;

Published online: 15 April 2014;

AJC-15024

In order to further apprehend chromophoric properties of phthalcyanine materials, a lipophilic tetra- $\beta$-(2-octanyloxy)-substituted nickel phthalocyanine was synthesized with a yield of $78 \%$ by a facile method without nitrogen protection and long-term heating performance. The synthetic compound was characterized by mass spectra, ${ }^{1} \mathrm{H}$ NMR, UV-visible, IR and elemental analysis, which were consistent with the proposed molecular structure. The compound not only behaved excellent solubility in many organic solvents, but also exhibited different chromophoric properties in various types of solvents, e.g., blue in isooctane and green in tetrahydrofuran. More interestingly, the chromophoric properties could be largely modulated by employed solvent, solution concentration and environment temperature.

Keywords: Phthalocyanine, Synthesis, Chromophoric property, Modulation.

\section{INTRODUCTION}

Phthalocyanine $(\mathrm{Pc})$ compounds are blue or green chromophores widely applied in many forefront areas such as functional films ${ }^{1,2}$, solar cells $\mathrm{s}^{3,4}$ and biological probes ${ }^{5,6}$, etc. All these applications are attributed to their uniquely large and flat $\pi$-conjugation systems localized over an arrangement of alternated carbon and nitrogen atoms ${ }^{7}$. Thus studying the nature of $\pi$ system and attempting to modulate $\pi$ system have been extensively and intensively investigated ${ }^{8}$. Typical examples are the preparation of asymmetrical phthalocyanines ${ }^{9}$, sub-phthalocyanines ${ }^{10}$, super-phthalocyanines ${ }^{11}$, aggregative phthalocyanines ${ }^{12}$ and various substituted phthalocyanines ${ }^{13}$. Among these phthalocyanine compounds, the substituted phthalocyanine derivatives are paid more attentions because it is easy for them to be synthesized and they usually behave excellent solubility in water or organic solvents ${ }^{14,15}$. To date, a number of substituted metal and metal-free phthalocyanines have been synthesized so as to modify phthalocyanine rings and find novel physicochemical properties ${ }^{11-14}$. But most of the interests are centralized on how new substituents situated around molecular periphery and diverse metals located in the center of phthalocyanine ring impact on the $\pi$ systems and therefore modulate the chromophoric properties of phthalocyanine compounds, few are mentioned of employed solvent, solution concentration and environment temperature being important ${ }^{10-15}$. However, this does not suggest that these external factors can be ignored, but implies that some potential consequences have not been adequately revealed from the corresponding phthalocyanine compounds. For further apprehending chromophoric properties of phthalocyanine molecules, here a lipophilic tetra- $\beta$-(2-octanyloxy)-substituted nickel phthalocyanine (ONPc) was synthesized by a facile method and its chromophoric properties were modulated by the aforesaid external factors. It was found that ONPc chromophore could sensitively respond to the alteration of employed solvent, solution concentration and environment temperature.

\section{EXPERIMENTAL}

DMSO was pre-dried over $\mathrm{BaO}$ and distilled under reduced pressure. All other reagents and solvents are commercial available and used without further purification. The synthesis, characterization and property study of ONPc were carried out according to follow procedure and method, respectivly.

General procedure: Synthesis of 4-(2-octanyloxy)phthalonitrile 3. $10.39 \mathrm{~g}$ 4-Nitrophthalonitrile $\mathbf{1}(60 \mathrm{mmol})$ and $7.81 \mathrm{~g}$ 2-octanol $2(60 \mathrm{mmol})$ were added to $100 \mathrm{~mL}$ anhydrous DMSO at room temperature. The reaction mixture was stirred and $3.6 \mathrm{~g} \mathrm{LiOH} \mathrm{(150} \mathrm{mmol)} \mathrm{was} \mathrm{interfused} \mathrm{over} \mathrm{a} 2 \mathrm{~h}$ period, and the mixture was then stirred and monitored by TLC. After 
1 day, the mixture was then poured into $300 \mathrm{~mL}$ of $10 \% \mathrm{NaCl}$ solution and extracted with $100 \mathrm{~mL}$ chloroform twice. The combined organic layer was washed by $100 \mathrm{~mL}$ water and dried with $\mathrm{Na}_{2} \mathrm{SO}_{4}$. The product was collected by removing solvent and further purified by flash column chromatography with chloroform as the mobile phase to afford light yellow and sticky liquid 4-(2-octanyloxy)phthalonitrile 3: $12.46 \mathrm{~g}$, yield: $81 \%$; b.p. $>200{ }^{\circ} \mathrm{C} ;{ }^{1} \mathrm{H}$ NMR $\left(500 \mathrm{MHz}, \mathrm{CDCl}_{3}\right): \delta$ 7.69 (d, 1H, ArH), 7.22 (s, 1H, ArH), 7.14 (d, 1H, ArH), 4.45 (m, 1H, OCH), $1.75\left(\mathrm{~m}, 2 \mathrm{H}, \mathrm{CH}_{2}\right), 1.62\left(\mathrm{~m}, 3 \mathrm{H}, \mathrm{CH}_{3}\right), 1.42$ $\left(\mathrm{m}, 2 \mathrm{H}, \mathrm{CH}_{2}\right), 1.28-1.35\left(\mathrm{~m}, 6 \mathrm{H}, \mathrm{CH}_{2} \mathrm{CH}_{2} \mathrm{CH}_{2}\right), 0.88(\mathrm{~m}, 3 \mathrm{H}$, $\left.\mathrm{CH}_{3}\right)$; $\mathrm{MS}\left(\mathrm{CHCl}_{3}\right): \mathrm{m} / \mathrm{z}$ calcd for $\left[\mathrm{M}+\mathrm{Na}^{+}\right]: 279.3$, found: 279.6 (an isotopic cluster peak) $\left[\mathrm{M}+\mathrm{Na}^{+}\right]$; IR $\left(\mathrm{KBr}, \mathrm{v}_{\max }, \mathrm{cm}^{-1}\right)$ : 2231 vs $(\mathrm{C}=\mathrm{N}), 1253$ vs $(\mathrm{C}-\mathrm{O}-\mathrm{C})$; $\mathrm{UV}$-visible $\left(\mathrm{CHCl}_{3}\right): \lambda_{\max }=$ 264, 302, $310 \mathrm{~nm}$. Anal. Calcd for $\mathrm{C}_{16} \mathrm{H}_{12} \mathrm{~N}_{2} \mathrm{O}$ (256.3): C 74.97, H 7.86, N 10.93, Found: C 74.93, H 7.63, N 10.85.

Synthesis of tetra- $\boldsymbol{\beta}$-(2-octanyloxy)-substituted nickel phthalocyanine (ONPc): $4.10 \mathrm{~g}$ Phthalonitrile derivative $\mathbf{3}$ (16.0 mmol), $0.95 \mathrm{~g} \mathrm{NiCl}_{2} \cdot 6 \mathrm{H}_{2} \mathrm{O}(4.0 \mathrm{mmol}), 10 \mathrm{~g}$ urea and $0.05 \mathrm{~g}\left(\mathrm{NH}_{4}\right)_{2} \mathrm{MoO}_{4}$ were mixed well and added in a $100 \mathrm{~mL}$ beaker. The beaker was covered with a watch glass and heated at $180{ }^{\circ} \mathrm{C}$ for $2 \mathrm{~h}$ in a heat-collection-type heater (DF-101S). After cooling, the resultant blue solid was ground and then washed with methanol by Soxhlet extraction to remove unreacted 3 and other remnants. In the end, the collected solid was purified by flash column chromatography with chloroform as the mobile phase to give pure blue solid ONPc: 3.39 g, Yield: $78 \%$; ${ }^{1} \mathrm{H}$ NMR (500 MHz, $\left.\mathrm{CDCl}_{3}\right): \delta 8.09-6.05(\mathrm{~m}$, broad, 12H, ArH), 4.77-4.93 (m, broad, 4H, 4OCH), 2.14$1.04\left(\mathrm{~m}\right.$, broad, $64 \mathrm{H}, 4 \mathrm{CH}_{3}\left(\mathrm{CH}_{2}\right)_{5}$ and $\left.4 \mathrm{CH}_{3}\right)$; $\mathrm{MS}\left(\mathrm{CHCl}_{3}\right)$ : $\mathrm{m} / \mathrm{z}$ calcd for $[\mathrm{M}]: 1082.6$, found: 1082.7 [M]; IR $\left(\mathrm{KBr}, \mathrm{v}_{\max }\right.$, $\mathrm{cm}^{-1}$ ): 1235 vs (C-O-C); Anal. Calcd for $\mathrm{C}_{64} \mathrm{H}_{80} \mathrm{~N}_{8} \mathrm{O}_{4} \mathrm{Ni}$ : C 70.91, H 7.44, N 10.34, Found: C 70.87, H 7.47, N 10.26.

Detection method: ${ }^{1} \mathrm{H}$ NMR spectra were recorded on an INOVA-500 spectrometer. IR spectra were measured on a Thermo FT-IR-200 spectrometer. UV-visible spectra were taken on a Shimadzu UV-visible-1800 spectrophotometer. MS spectra were obtained on a LDI-1700-TOF mass spectrometer. Elemental analyses were performed on a Perkin-Elmer 2400 Elemental Analyzer.

UV-visible analysis of ONPc: The solution of ONPc in various solvents was prepared by weighing and diluting methods.
Namely, the thick solution was first prepared, and then the suitable quantity of thick solution was diluted into the required concentration for analysis on a UV-visible 1800 Spectrophotometer.

The solid ONPc film employed in UV-visible analysis was obtained by immersing a piece of clear quartz slice $(10 \times$ $10 \times 0.2 \mathrm{~mm})$ in a $10 \mathrm{~mL}$ solution $\left(8 \times 10^{-5} \mathrm{~mol} \mathrm{~L}^{-1}\right.$, in isooctane $)$ in a $50 \mathrm{~mL}$ beaker, and enveloping the beaker with filter paper and then setting it for 3 days in air. The UV-visible analysis at different temperature was mainly recurred to an equipped lowconstant-temperature bath using water as the heating and cooling media. Cycled water can pass the colormetric stand through the insulating hoses to make the sample solution in quartz flow-cell (10 $\mathrm{mm}$ path length) maintain the same temperature as water. Although water temperature is indicated by an electronic meter furnished in this spectrophotometer, a thermometer is still put into water to show correct water temperature. Before measurements, the solutions in the quartz cell sealed tightly with a quartz cover were pretreated for $10 \mathrm{~min}$ in the isothermal water.

\section{RESULTS AND DISCUSSION}

The common synthesis of lipophilic metal phthalocyanines was carried out by heating substituted phthalonitriles and inorganic salt at $135{ }^{\circ} \mathrm{C}$ for more than $12 \mathrm{~h}$ in presence of DBU as catalyst in a suitable organic solvent and under nitrogen atmosphere ${ }^{16}$. Though the reaction temperature was comparatively low, the long reaction time and nitrogen protection did not benefit performance, and also the final yield usually was not over $60 \%$. In order to facilitate synthesis, the substrate-melting synthetic method generally employed in preparation of hydrophilic substituted metal phthalocyanines was imported ${ }^{17}$ and accordingly a facile protocol for synthesis of lipophilic ONPc was designed as in Scheme-I. By this means, the substituted phthalonitriles $\mathbf{3}$ and nickel salt were melted at $180{ }^{\circ} \mathrm{C}$ for $2 \mathrm{~h}$ in the presence of $\left(\mathrm{NH}_{4}\right)_{2} \mathrm{MoO}_{4}$ as catalyst in melted urea. After purified by column chromatography, the ONPc yield was about $78 \%$. Comparing with the routine way of lipophilic phthalocyanines synthesized in solution ${ }^{16}$, here the synthetic method not only gave a high yield more than $70 \%$ but also was more facile due to no nitrogen protection and long-term heating performance.<smiles>N#Cc1ccc([N+](=O)[O-])cc1C#N</smiles>

1

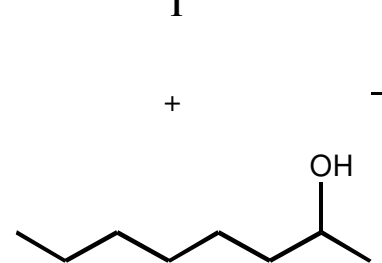

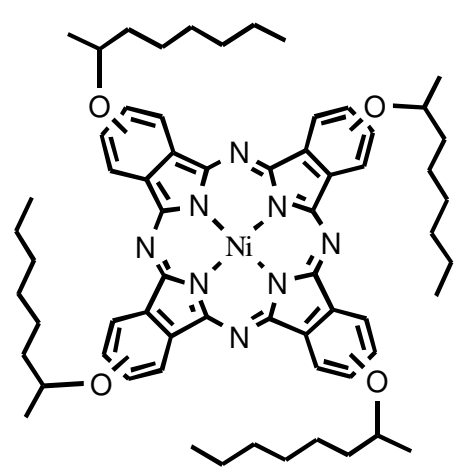


Tetra- $\beta$-(2-octanyloxy)-substituted nickel phthalocyanine was characterized by mass spectra, ${ }^{1} \mathrm{H}$ NMR, UV-visible, IR and elemental analysis, which were consistent with the proposed structure in Scheme-I. In the mass spectrum, the peak of singly charged molecular ion was obvious and moreover a weak peak of dimer could be distinguished, which meant that phthalocyanine molecules were inclined to aggregate (Fig. 1). The ${ }^{1} \mathrm{H}$ NMR spectrum was strongly impacted by paramagnetism of the center $\mathrm{Ni}(\mathrm{II})$ in a square planar environment ${ }^{17}$, which resulted in that ONPc displayed three broad bands in ${ }^{1} \mathrm{H}$ NMR spectra:

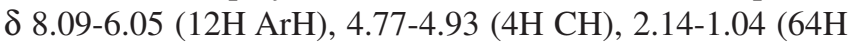
$\mathrm{CH}_{2}$ and $\left.\mathrm{CH}_{3}\right)$. The IR absorption at $1235 \mathrm{~cm}^{-1}(\mathrm{C}-\mathrm{O}-\mathrm{C})$ meant the characteristic vibration of chemical bond linking 2-octanyloxy group to phthalocyanine ring. The UV-visible spectra and chromophoric properties of ONPc were discussed.

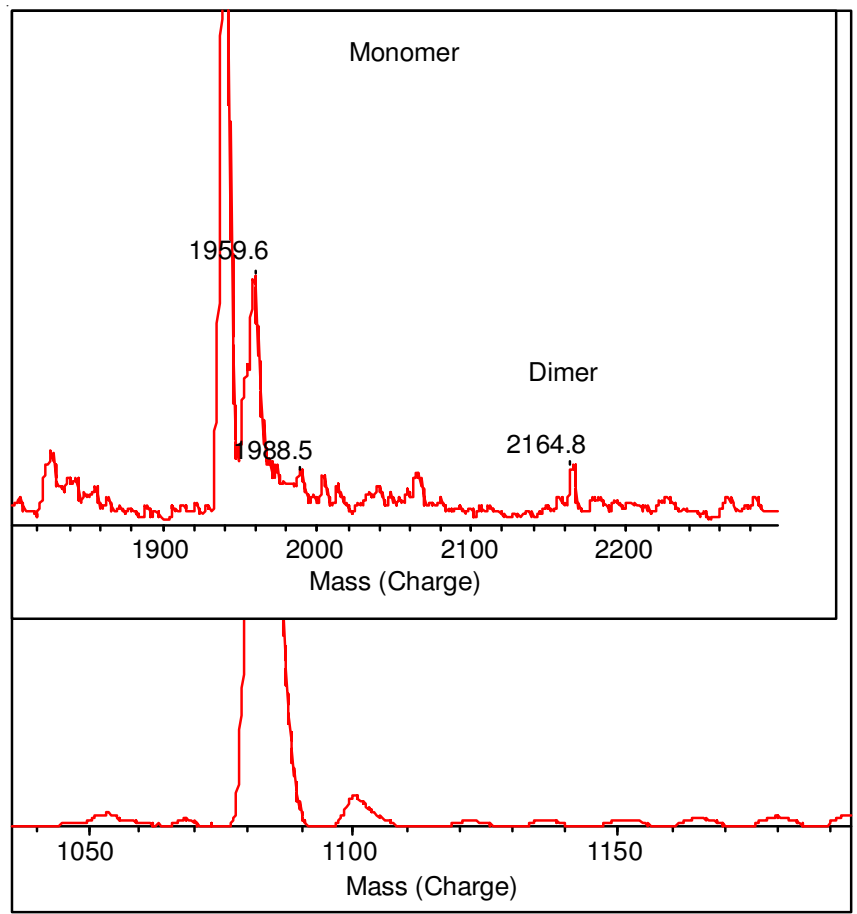

Fig. 1. TOF mass spectra of ONPc: $m / z, 1082.7$ for monomer; 2164.8 for dimer

The synthetic ONPc have four 2-octanyloxy groups around macromolecular ring and thereby it can be dissolved in many organic solvents, but the solubility is different in various types of solvents (Table-1). It was hard dispersed by small molecule solvents, e.g, methanol and acetone, or by high polar solvents, e.g, DMF and DMSO. In ethanol and propanol, ONPc dissolved slowly and slightly. In some bulky or suitable polar molecules, the phthalocyanine compound behaved excellent solubility. The soluble diversity was attributed to the difference of affinity between solvent and phthalocyanine molecules ${ }^{18}$. In terms of ONPc structure, the long alkyl chain and weak polarity of 2-ocatanyloxy groups allowed it to be dissolved in those organic molecules with enough size and/or suitable polarity based on the similarity and intermiscibility principle. The fine solubility implied that solvents could sufficiently conquer the aggregation among phthalocyanine rings and dispersed them well. The more interesting thing was that ONPc molecules behaved very unlike chromophoric properties in various types of solvents, e.g., being blue in isooctane and green in THF (Fig. 2 solutions in two bottles). The phenomena could be analyzed based on the UV-visible spectra of ONPc in two solvents (Fig. 2). In THF, ONPc like those usual substituted metal phthalocyanines displayed a standard UV-visible spectrum with a narrow Q band at $676 \mathrm{~nm}$, which meant that phthalocyanine molecules had been dispersed into molecular monomers ${ }^{16}$. In isooctane, it gave an abnormally broad Q band at $668 \mathrm{~nm}$, and a broader and stronger shoulder peak at $609 \mathrm{~nm}$. All these were the evidences that some phthalocyanine molecules had stacked by H-aggregation pattern, namely face-to-face fashion ${ }^{19}$. H-aggregation usually occurred among hydrophilic phthalocyanine molecules due to the high hydrophobicity of phthalocyanine rings in water, and those lipophilic phthalocyanines were seldom found having this aggregation in organic solvents ${ }^{16}$. The H-aggregation among lipophilic ONPc molecules in isooctane might be comprehended by the interaction between solute and solvent molecules. In solution, there were two molecular interactions related to ONPc dissolution. One was the interaction between solvent and solute molecules, favoring dissolution. Another one was the stacking among ONPc flat $\pi$ systems, helping $\mathrm{H}$ aggregation. In THF, the solvent molecules interacted on not only the long alkyl chain but also the oxygen of substituents as well as the center $\mathrm{Ni}$ (II), which was enough to overcome the intermolecular $\pi$ stacking force and disperse ONPc into molecular monomers. Comparing with THF, isooctane molecules mainly pulled the long alkyl chain of 2-octanyoxyl groups, which does not adequately prevented the $\pi$ stacking,

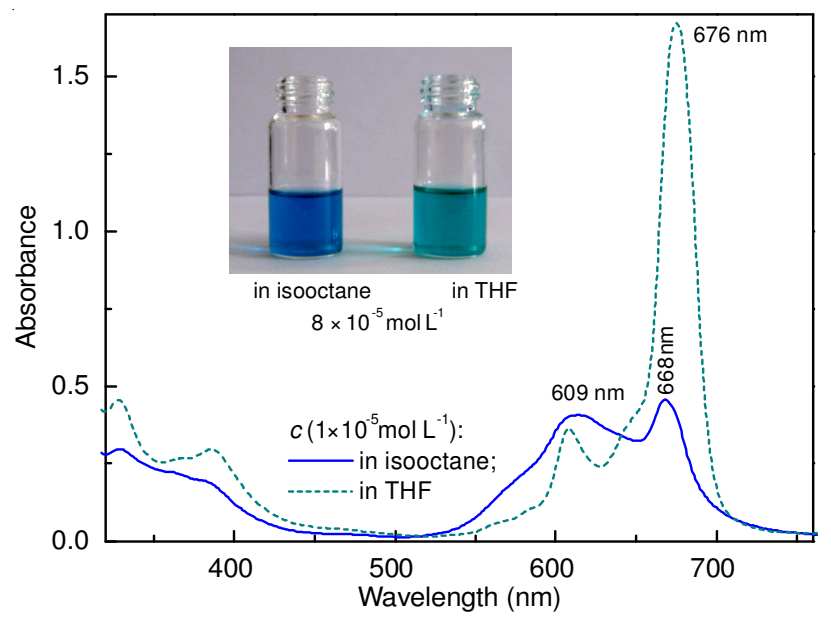

Fig. 2. Colours (up) and UV-visible spectra (down) of ONPc in isooctane and THF

TABLE-1

SOLUBILITY OF ONPC IN VARIOUS ORGANIC SOLVENTS

\begin{tabular}{|c|c|c|c|c|c|}
\hline \multirow{2}{*}{ Solubility } & \multirow{2}{*}{ Hard } & \multirow{2}{*}{ Slight } & \multicolumn{3}{|c|}{ Easy } \\
\hline & & & \multicolumn{3}{|c|}{ Blue $\longrightarrow$ Green solution } \\
\hline Solvents & $\begin{array}{l}\text { Methanol, acetone, } \\
\text { DMF, DMSO }\end{array}$ & Ethanol, propanol & $\begin{array}{l}\text { Butanol, petroleum } \\
\text { ether, isooctane }\end{array}$ & $\begin{array}{l}\text { Octanol, ethyl acetate, } \\
\text { ethyl ether, triethylamine }\end{array}$ & $\begin{array}{l}\text { Chloroform, THF, paraffin, } \\
\text { aromatic hydrocarbons }\end{array}$ \\
\hline
\end{tabular}


and left a few ONPc molecules to aggregate slightly in isooctane. The results were that the $\mathrm{Q}$ band appeared hypochromic effect at $668 \mathrm{~nm}$ and the shoulder peak presented strong hyperchromic effect at $609 \mathrm{~nm}$. Thus the solution was blue instead of green as in THF. This showed that ONPc chromophore could be remarkably modulated by suitable solvents.

Although paraffin like isooctane was also mainly consisted of alkyl hydrocarbons, ONPc was green in paraffin and had a narrow Q band at $675 \mathrm{~nm}$ (Fig. 3 a). This should result from the strong interaction between bulky paraffin molecules and 2-octanyloxy groups around phthalocyanine rings, for widely known that the bulkier the molecule is, the stronger interaction it gives. The similar situation could be met in the other types of solvents, e.g., 1-butanol and 1-octanol. ONPc dissolved slowly in 1-butanol and gave a broad Q band as in isooctane, but dissolved well in 1-octanol and presented a slightly nice $\mathrm{Q}$ band at $676 \mathrm{~nm}$ (Fig. 3 b).

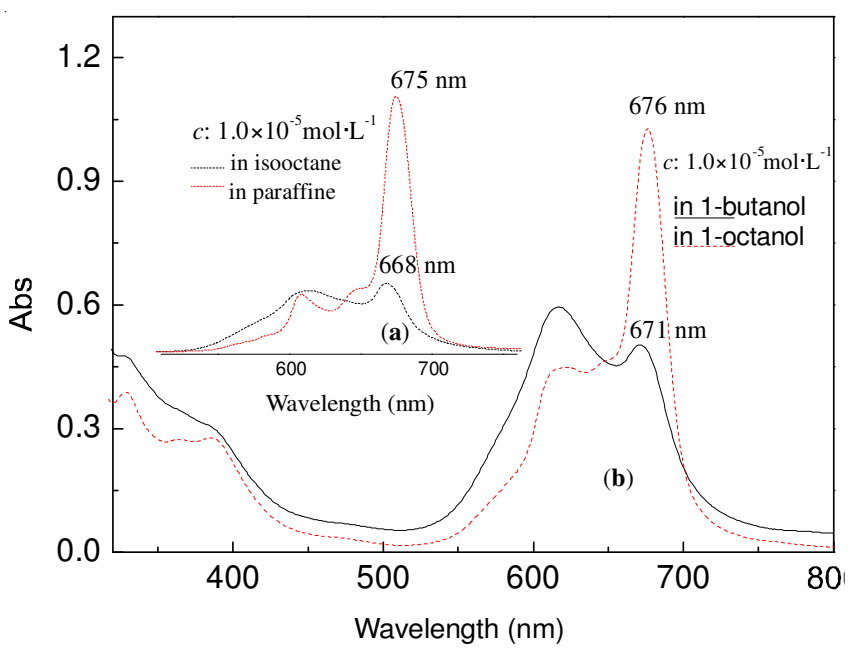

Fig. 3. UV-visible spectra of ONPc in size-different organic molecules

The solvent polarity also gave obvious impact on the ONPc chromophore. Ethyl ether had elemental compositions similar to THF, but it was endowed with weak polarity for the better molecular symmetry. The result was that ethyl ether could not disperse ONPc well and only offered it with a broad Q absorption band at $669 \mathrm{~nm}$ (Fig. 4a). Contrarily, chloroform with suitable polarity in despite of being little molecule could dissolve ONPc very well and present it with a narrow Q band at $678 \mathrm{~nm}$. And the Q band did not distort following concentration alteration (Fig. 4b). But the more high polarity was not helpful for employed solvents, e.g., DMF and DOSO, to disperse ONPc on account of disobeying the similarity and intermiscibility principle (Table-1). Now that the suitable polarity was another favorable factor for solvent to dissolve ONPc, then ONPc chromophore might be modulated by altering solvent polarity via mixing one into another solvent. This was agreed with the fact that THF, gradually mixed into solution of ONPc in isooctane, induced hyperchromic effect, Q band narrowing and a red shift from $668 \mathrm{~nm}$ to $671 \mathrm{~nm}$ (Fig. 4c).

Unlike isooctane, aromatic hydrocarbons were very favorable in dispersing ONPc (Table-1) and provided it with a narrow $\mathrm{Q}$ band (Fig. 5). In cinnamene, ONPc appeared a narrow $\mathrm{Q}$ band at $679 \mathrm{~nm}$ and the absorption was impacted

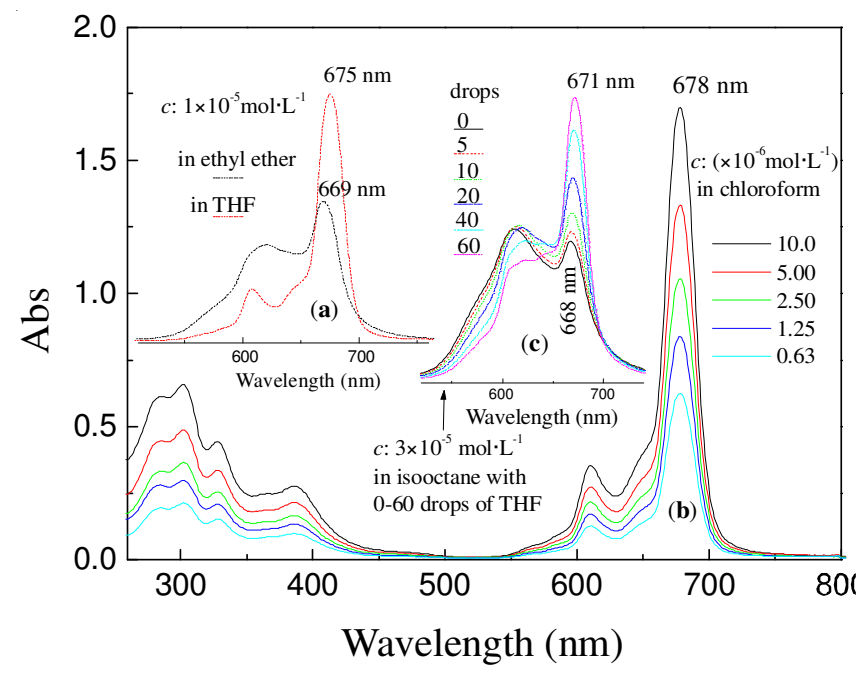

Fig. 4. UV-visible spectra of ONPc in organic solvents with various polarities

slightly even if isooctane was mixed into cinnamene. The mixed solvent of cinnamene and isooctane (2:1, v:v) only cause $\mathrm{Q}$ band with a slightly hypochromic effect and a $2 \mathrm{~nm}$ blueshift from 679 to $677 \mathrm{~nm}$. The mixed solvent of cinnamene and isooctane $(1: 2, \mathrm{v}: \mathrm{v})$ induced $\mathrm{Q}$ band with an obviously hypochromic effect and a $5 \mathrm{~nm}$ blue-shift from 679 to 674 $\mathrm{nm}$, but the Q band still was normal profile (Fig. 5a). Whereas a few drops of cinnamene were mixed into isooctane, then hyperchromic effect appeared obviously at $668 \mathrm{~nm}$ (Fig. 5b). The aforesaid phenomena showed that cinnamene greatly interacted with ONPc molecules and dispersed them well. Comparing with isooctane, cinnamene had a $\pi$ conjugation benzene ring and hence the hydrocarbon not only pulled 2octanyloxy groups but also attracted the large $\pi$ system of ONPc by $\pi-\pi$ interaction similar to Pc-Pc stacking ${ }^{19}$. It was the two affinities that dispersed ONPc well in cinnamene.

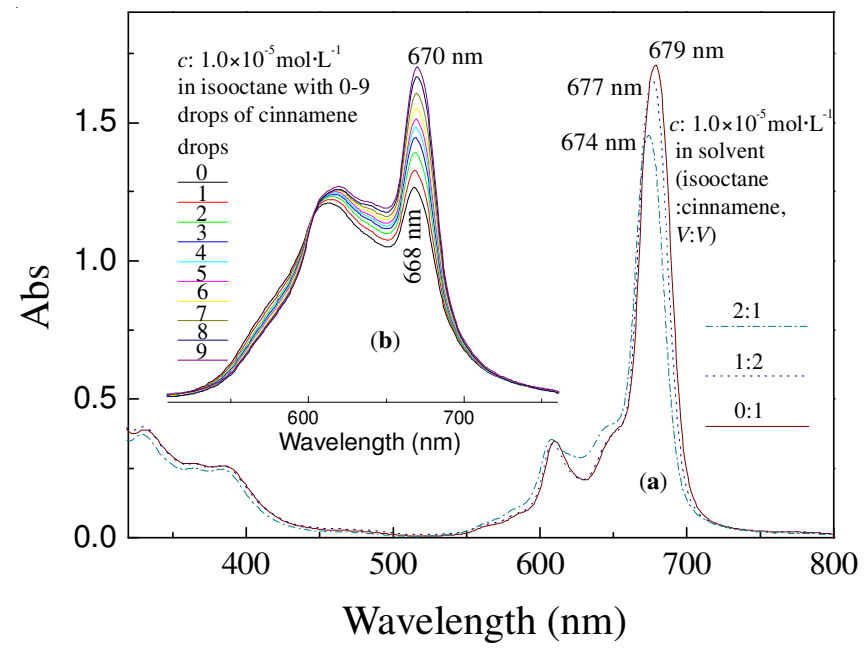

Fig. 5. UV-visible spectra of ONPc in cinnamene, isooctane and mixed solvent

The fact that ONPc dissolved well but preferred aggregation in isooctane revealed that the space between two adjacent phthalocyanine molecules was not enough to prevent intermolecular aggregation. Well then diluting solution might pull them apart from one another and help to lessen aggregation. Therefore the solution of ONPc in isooctane was diluted 
TABLE-2

PHYSICAL PARAMETERS OF ONPC IN ISOOCTANE

\begin{tabular}{|c|c|c|c|c|c|c|c|c|c|c|c|c|c|c|}
\hline Parameters & \multicolumn{14}{|c|}{ Corresponding data } \\
\hline \multirow{2}{*}{$\mathrm{c}^{\mathrm{a}}\left(\times 10^{-\mathrm{x}} \mathrm{mol} \mathrm{L}^{-1}\right)$} & & \multicolumn{4}{|c|}{$x=5$} & \multicolumn{3}{|c|}{$x=6$} & \multicolumn{3}{|c|}{$x=7$} & \multicolumn{3}{|c|}{$x=8$} \\
\hline & & 8.0 & 4.0 & 2.0 & 1.0 & 5.0 & 2.5 & 1.3 & 6.3 & 3.1 & 1.6 & 7.8 & 3.9 & 2.0 \\
\hline $104 I^{-1-1}$ & $\mathrm{Q}^{\mathrm{c}}$ & 1.8 & 2.3 & 3.2 & 4.3 & 6.0 & 8.2 & 11 & 15 & 20 & 25 & 30 & 54 & 70 \\
\hline$\varepsilon^{\circ}\left(\times 10^{-} \mathrm{L} \mathrm{mol}^{-1} \mathrm{~cm}\right)$ & $S^{d}$ & 2.3 & 2.7 & 3.1 & 3.5 & 3.9 & 4.2 & 4.6 & 4.8 & 5.4 & 5.8 & 7.7 & 13 & 15 \\
\hline
\end{tabular}

${ }^{\mathrm{a}}$ Concentration of ONPc in isooctane, ${ }^{\mathrm{b}}$ Molar extinction coefficient, ${ }^{\mathrm{c}} \mathrm{Q}$ band around $667 \mathrm{~nm},{ }^{\mathrm{d}}$ Shoulder peak around $609 \mathrm{~nm}$

gradually by two folds once and it was found that dilution caused the shoulder peak at $609 \mathrm{~nm}$ decrease relative to the $\mathrm{Q}$ band at $667 \mathrm{~nm}$ (Fig. 6a), which meant that aggregation was gradually weaken. Accordingly the Q band had a 39-fold increase in molar extinction coefficient $(\varepsilon)$ from 1.8 to $70 \times$ $10^{4} \mathrm{~L} \mathrm{~mol}^{-1} \mathrm{~cm}$ and the shoulder peak only had a 6.5 fold increase in $\varepsilon$ from 2.3 to $15 \times 10^{4} \mathrm{~L} \mathrm{~mol}^{-1} \mathrm{~cm}$ (Table-2). When the concentration decreased down to $6.3 \times 10^{-7} \mathrm{~mol} \mathrm{~L}^{-1}$, the $\mathrm{Q}$ band had already turned into a normal profile and gave a red shift from 667 to $669 \mathrm{~nm}$ (Fig. 6b). These changes illuminated that $\mathrm{H}$-aggregation in dilute solution of ONPc in isooctane became difficult due to lengthening phthalocyanine-intermolecular space. Certainly ONPc should be inclined to aggregate greatly in solid, which could be concluded by the exceptionally broad Q band of solid ONPc film (Fig. 6c).

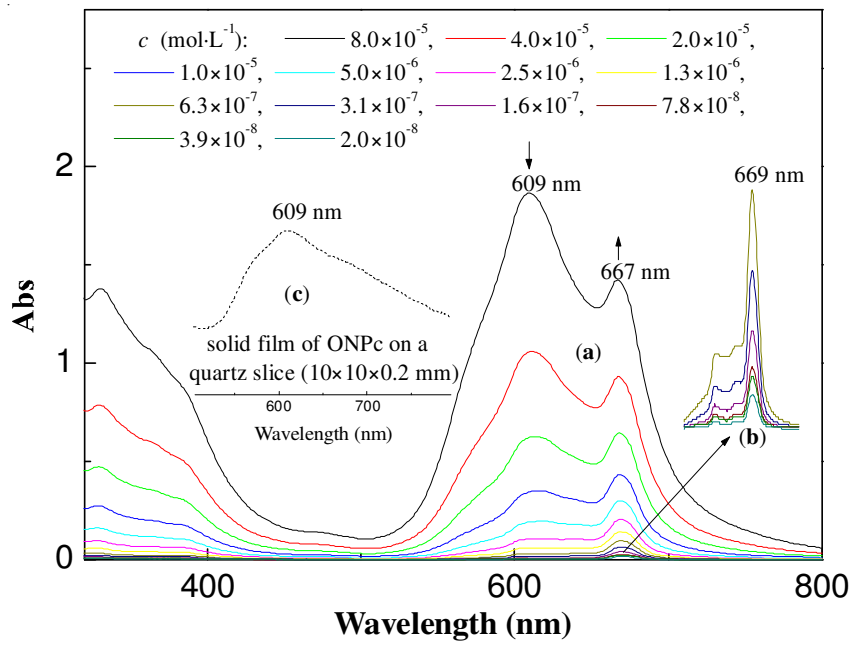

Fig. 6. UV-visible spectra of ONPc in isooctane and solid film

Based on molecular thermodynamics, high temperature caused liquid molecules move more intensively to overcome intermolecular interaction ${ }^{20}$. In terms of ONPc molecules, the intermolecular stacking among them in isooctane should be influenced by temperature and accordingly its chromophoric properties also should be altered. It was found that the $\mathrm{Q}$ band of ONPc in isooctane exhibited obviously hyperchromic effect at $50{ }^{\circ} \mathrm{C}$ and contrarily appeared hypochromic effect at $0{ }^{\circ} \mathrm{C}$, relative to the absorbance at $25^{\circ} \mathrm{C}$ (Fig. 7a). The temperaturedependent chromophoric properties were also observed in the solutions of ONPc in other solvents, e.g., paraffin (Fig. 7b). It was obvious that the higher temperature could availably activate ONPc molecules into energetic molecules to resist intermolecular stacking and induce the hyperchromic effect of Q band.

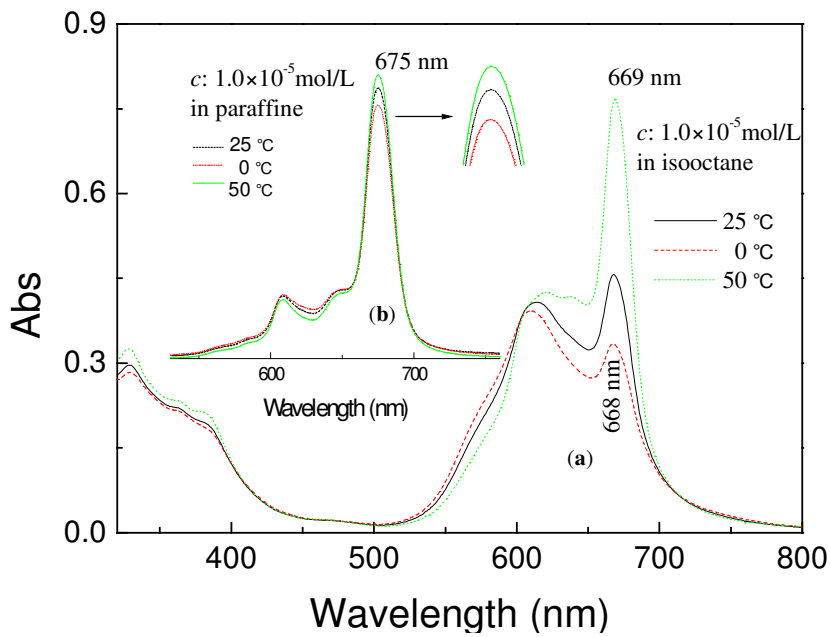

Fig. 7. UV-visible spectra of ONPc in isooctane and paraffine at different temperatures

\section{Conclusion}

A facile method was imported to synthesize lipophilic ONPc by modifying the strategy employed in preparation of hydrophilic phthalocyanine compounds. The method not only could improve resultant yield up to $78 \%$ but also largely cut reaction time down to $2 \mathrm{~h}$, and also needed not nitrogen protection. ONPc behaved excellent solubility in various organic solvents, but showed greatly different chromophoric properties in them. In small or weakly polar molecules, it exhibited blue due to intermolecular H-aggregation. In those bulky, suitable polar or aromatic molecules, it displayed green for phthalocyanine molecules dispersed well. After diluted, ONPc in isooctane appeared obviously hyperchromic effect at Q band for large phthalocyanine-intermolecular space weakening $\mathrm{H}$ aggregation. In addition, higher temperature also induced hyperchromic effect of Q band for energetic phthalocyanine molecules effectively resisting intermolecular stacking.

\section{ACKNOWLEDGEMENTS}

The authors thank the National Natural Science Foundation of China (20530115) and the $41^{\text {st }}$ Postdoctoral Science Foundation of China, for financial support.

\section{REFERENCES}

1. W. Li, A. Yu, D.C. Higgins, B.G. Llanos and Z. Chen, J. Am. Chem. Soc., 132, 17056 (2010).

2. T. Rawling and A. McDonagh, Coord. Chem. Rev., 251, 1128 (2007).

3. M.G. Walter, A.B. Rudine and C.C. Wamser, J. Porphyr. Phthalocyanines, 14, 759 (2010).

4. J. Bartelmess, B. Ballesteros, G. de la Torre, D. Kiessling, S. Campidelli, M. Prato, T. Torres and D.M. Guldi, J. Am. Chem. Soc., 132, 16202 (2010). 
5. L. Orzel, A. Janczyk, M. Brindell, G. Stopa and G. Stochel, J. Coord. Chem., 63, 2695 (2010).

6. H. Ali, S. Ait-Mohand, S. Gosselin, J.E. van Lier and B. Guérin, J. Org. Chem., 76, 1887 (2011).

7. Z. Ni, R. Li and J. Jiang, Struct. Bond., 133, 121 (2009).

8. J. Mack and N. Kobayashi, Chem. Rev., 111, 281 (2011).

9. A.O. Naumov, E.V. Kudrik and G.P. Shaposhnikov, Chem. Heterocycl. Compd., 40, 469 (2004).

10. D. Wróbel, A. Boguta and P. Mazurkiewicz, Spectrochim. Acta A, 59, 2841 (2003)

11. E.A. Cuellar and T.J. Marks, Inorg. Chem., 20, 3766 (1981).

12. E.T. Saka, C. Göl, M. Durmus, H. Kantekin and Z. Biyiklioglu, J. Photoch. Photobio. A, 241, 67 (2012).

13. T. Nyokong, Coord. Chem. Rev., 251, 1707 (2007).
14. H.I. Beltra'n, R. Esquivel, A. Sosa-Sa'nchez, J.L. Sosa-Sánchez, H. Höpfl, V. Barba, N. Farfán, M. Galicia García, O. Olivares-Xometl and L.S. Zamudio-Rivera, Inorg. Chem., 43, 3555 (2004).

15. L. Zhang, D. Qi, L. Zhao, Y. Bian and W. Li, J. Mol. Graph. Model., 35, 57 (2012).

16. Q. Cai, W. Zhu, H. Zhang, Y. Zhang and D. Ma, Synthesis, 741 (2005).

17. F.D. Cong, B. Ning, X.G. Du, C.Y. Ma, H.F. Yu and B. Chen, Dyes Pigments, 66, 149 (2005)

18. N.S. Lebedeva, E.V. Trofimova, N.A. Pavlycheva and A.I. Vyugin, Russ. J. Org. Chem., 38, 1195 (2002).

19. A. Günsel, M.N. Yarasir, M. Kandaz and A. Koca, Polyhedron, 29, 3394 (2010).

20. N.S. Lebedeva, N.A. Pavlycheva, E.V. Parfenyuk and A.I. Vyugin, J. Chem. Thermodyn., 38, 165 (2006). 